\title{
COVID-19: Current Status and Future Strategies to Control the Spread in the State of Tamil Nadu, India
}

\author{
Selva Ganesh S. ${ }^{1}$, Ravanth Kumar Chandran ${ }^{2}$, Lambodaran G. ${ }^{3}$, Pedamally Manodh ${ }^{4}$ \\ ${ }^{1}$ Assistant Professor, Department of Oral Pathology and Microbiology, Faculty of Dentistry-Meenakshi Ammal \\ Dental College and hospital, Meenakshi Academy of Higher Education and Research, Chennai, ${ }^{2}$ Assistant \\ Professor, Department of Orthodontics and Dentofacial Orthopedics, Faculty of Dentistry-Meenakshi Ammal \\ Dental College and hospital, Meenakshi Academy of Higher Education and Research, Chennai, ${ }^{3}$ Associate \\ Professor, Department of Prosthodontics, Faculty of Dentistry-Meenakshi Ammal Dental College and Hospital, \\ Meenakshi Academy of Higher Education and Research, Chennai, ${ }^{4}$ Associate Professor, Department of Oral and \\ Maxillofacial Surgery, Faculty of Dentistry-Meenakshi Ammal Dental College and hospital, Meenakshi Academy \\ of Higher Education and Research, Chennai
}

\begin{abstract}
The severe acute respiratory syndrome coronavirus 2 from the family of Coronaviridae is causing coronavirus disease. This is a zoonotic disease and identified first in the Hubei Province of China. In early 2020, this disease was announced as a global pandemic. The pandemic hit the nations undiscriminating their economic and development status. Tamil Nadu, a state of India is one of the most affected in the country. In spite of various precautionary measures in controlling the pandemic, the state recorded active cases of 18,881 as of $13^{\text {th }}$ June 2020 . With no defined treatment to cure the disease till date, the healthcare workers along with the collective support of various departments of the state are handling the situation with an aim to end the epidemic. Almost all the sectors such as finance, business, education, etc. were affected by the pandemic. This article discusses the current countermeasures for the infection, the impact on the state and suggests a few strategies to control the spread.
\end{abstract}

Keywords: SARS-CoV-2, COVID-19, Pandemic, Tamil Nadu, Epidemic, Strategies, Lockdown.

\section{Introduction}

The severe acute respiratory syndrome coronavirus 2 (SARS-CoV-2) is a new strain from the family of Coronaviridae which mainly targets the respiratory system of humans causing coronavirus disease (COVID-19). It was first discovered at the end of the year 2019 when a group of patients were admitted with reports of pneumonia, in the hospitals of Hubei Province

\section{Corresponding Author:}

\section{Dr. Selva Ganesh S.}

Assistant Professor, Department of oral Pathology and Microbiology, Faculty of Dentistry-Meenakshi Ammal Dental College and hospital, Meenakshi Academy of Higher Education and Research, Chennai e-mail: drselva.oralpathology@madch.edu.in of China. This disease is a zoonotic disease which means it is transmissible from animals to humans. This is more similar to earlier reported diseases like Severe Acute Respiratory Syndrome (SARS) and Middle East Respiratory Syndrome (MERS). Since it is genetically similar to SARS, it is name named as SARS-CoV-2 on $11^{\text {th }}$ February 2020 by the International Committee on Taxonomy of Viruses (ICTV). The common symptoms of COVID-19 include fever, cough, sputum production, tiredness, anosmia and breathing difficulties ${ }^{[2,5,17]}$. In serious cases, this can cause pneumonia, kidney failure and even death. The symptoms of the disease appear after 5.2 days of the incubation period ${ }^{[2]}$. Patients with mild symptoms recover after a week, whereas patients with severe symptom cases due to alveolar damage caused by virus experience progressive respiratory failure leading to death. However, factors such as the patient's age and immune system have a large impact 
in recovering from the disease. In case studies, deaths are recorded in middle age and elderly patients with pre-existing diseases. COVID-19 disease has shown an unremitting capacity to infect the population of the world ${ }^{[3]}$. When the disease outbreak reached almost all the nations within a few weeks with the reported cases of 53,401 , WHO declared the disease as a global pandemic on $11^{\text {th }}$ March 2020 . As on $13^{\text {th }}$ June 2020 , globally there are about 7.8 million COVID-19 active cases causing more than 4 lakhs deaths and 4 million recoveries. The pandemic hit the nations undiscriminating their economic and development status. Industrialized countries like the USA, Italy are not exceptions but the most affected.

The developing country like India is no exception for this global health emergency. The first COVID-19 positive case in India was identified on $30^{\text {th }}$ January 2020 in the state of Kerala. As on June, $13^{\text {th }}$ India ranks $4^{\text {th }}$ worldwide and $1^{\text {st }}$ in Asia for having the largest number of COVID-19 positive patients with active cases of 150,101 out of 55,07,182 samples tested [31]. Tamil Nadu is one of the most affected states in India. In Tamil Nadu, the first case of COVID-19 positive was identified on the $7^{\text {th }}$ of March 2020. As on June 14, according to the Health and Family Welfare Department of the Government of Tamil Nadu, the state has identified 42,687 positive cases out of 691,817 persons tested. Tamil Nadu is at $3^{\text {rd }}$ place in having the largest number of active cases $(18,881)$ and $2^{\text {nd }}$ place in the number of patients recovered $(23,409)$ from the disease. Maharashtra and Delhi are having a greater number of active cases than Tamil Nadu [7]. Of the 38 districts of the state, the state capital Chennai is the most affected with active cases of 30,444 comprising $71 \%$ and 316 deaths of the infected patients as on $13^{\text {th }}$ June $2020^{[16]}$.

Control Measures: COVID-19 is an influenzalike disease that is highly contagious. There is no definite treatment to date available for the treatment of COVID-19. Only supportive therapies available for COVID-19 are antibiotics for infection, mechanical ventilation system, administration of analgesic and antipyretic and maintenance of hydration. Some of the studies claimed that interferon-alpha and ribavirin to be showing synergistic effect in early stages and some studies suggested mycophenolic acid as monotherapy [19]. World Health Organization recommended extracorporeal membrane oxygenation (ECMO) to patients with refractory hypoxemia, treatment with convalescent plasma and immunoglobulin $G$ delivered to the critical condition patients. Remdesivir has been reported to treat the first US case of COVID-19 successfully ${ }^{[13,14]}$. In order to prevent the transmission, WHO announced various infection prevention and control (IPC) strategies such as to wash the hands frequently using alcohol-based solutions, avoid the touching of nose, eyes, mouth, wearing of face masks, social distancing, use of disinfectants, etc ${ }^{[30]}$. This was seconded by the government of the state and public awareness through print and electronic media was made.

To decrease the impacts caused by the novel coronavirus and to reduce its transmission, state government along with the central government took various precautionary measures and various activities to control the disease spread. The Indian government has allotted 510 crore rupees to the state of Tamil Nadu to fight against the spread of disease. Earlier in February, Tamil Nadu has allocated $5.7 \%$ of its total expenditure on health in the state budget 2020-2021 This accounts for about 17,000 crores rupees which is greater than the average expenditure of 29 states of India. From the announcement of COVID-19 to be a disaster till June 4 , the state government has allotted about 4,333 crore rupees. The planning in the state like most other states and nations was subjugated by measures to stop the spread of the virus. Since the identified cases had a travel history of infected nations, restriction on airports and temperature screening of the passengers was made. State government reports that more than 2.2 lakhs people have been screened at the airports. The passenger screening was extended to railway stations, bus stations and many public gathering buildings. And those showing symptoms were treated in hospitals. Humanoid robots are used in hospitals for servicing the infected patients. Followed by COVID-19 diagnosis screening and compulsory quarantine of people coming into the state was advised.

On March 23, the day after the number of positive cases increased to 9, the Government of Tamil Nadu announced state-level lockdown for March 24-31 followed by the announcement of a nation-wide lockdown of 21 days on the next day by the Government of India. This was welcomed by most of the people of the state. Lockdown led to complete closures of the borders, restriction in the inter and intra-state movement, a shutdown of all private and government organizations, public gatherings, etc. To ensure the availability of the essentials to the public, travel between states and inside the sates was exempted for some essential commodities. E-passes were made mandatory for travel within the 
state to deliver the essentials and for some emergency situations. At the community level, the government started screening of persons who had come to the state from various infected nations. In order to prevent the community-spread, the state started sanitizing the streets and roads using disinfectant powders and sprays, which was later reported to be an inefficient method by WHO. The government took various quick responses and initiatives, such as preparedness by following the Standard Operating Procedure (SOP) in government hospitals - case definitions, laboratory protocols, case transport guidelines, preventive measures, hospital and ambulance disinfection protocols and case management. All the health care professionals treating or screening the COVID-19 cases were advised to use personal protective equipment (PPE) with masks. Considering the requirement more healthcare workers and experts were appointed on a temporary basis to serve during the pandemic. While critical screening of people with symptoms was going on, a sudden increase in the number of asymptomatic cases reduced the effectiveness of the previously conducted screening. More than $80 \%$ of the reported COVID-19 positive cases in the state are asymptomatic. Indian Council of Medical Research (ICMR) reported that airport screening, quarantine measures help to delay epidemic to a maximum of three days ${ }^{[1]}$. And also suggested the need to test for symptomatic people with no travel history. So, the state government began to test all the peoples with severe pneumonia ${ }^{[23]}$. For daily updates, a dashboard has been created officially which displays the district-wise number of tests conducted, active cases, recovered cases and deaths

After facing criticism for having tested a very low number of persons, the testing for the disease scaledup over the time from totally 498 persons tested till $24^{\text {th }}$ March to over 16,000 persons tested per day with 72 approved testing centers all over the state as of $12^{\text {th }}$ June. The persons who had direct contact with the positive cases were also screened, isolated and given treatment. The case identification was made available and accessible with the implementation of ICMR's labbased surveillance. To identify the infections, protocols suggested by WHO, ICMR is being followed. The most recommended method of diagnosis is nasopharyngeal and oropharyngeal swab. SARS-CoV-2 RNA is detected $63 \%$ in nasal swabs compared to oropharyngeal swab (32\%) ${ }^{[26]}$. For diagnosing the COVID-19 in patients many of the assays are uses such as Rapid antigen lateral flow assay, Serological method, random amplification deep sequencing method, Real-Time PCR assay (RTPCR), loop-mediated isothermal amplification, multiplex isothermal amplification followed by microarray detection, and CRISPR (clustered regularly interspaced short palindromic repeats)-based assays. The RT PCR assay is recommended for molecular testing of coronavirus. It minimizes the false-positive result associated with the amplification of product contamination [28, 29]. Till date, the state has 123 government hospitals and 169 private hospitals to treat SARS-CoV-2 infected patients. So far, the state has procured about 14 lakhs testing kits for diagnosis purposes. Based on the categories of symptoms and asymptomatic conditions, the patients are admitted one of the 3 categories of health facilities all over the state. The state has 167 centers under Category I - COVID Care Center (CCC), 105 centers under Category II - Dedicated COVID Health Center (DCHC) and 69 centers under Category III - Dedicated COVID Hospital (DCH).

All the abovesaid measures were taken only for limiting the rate of transmission and to decrease the epidemic peak. With these measures, as on $12^{\text {th }}$ June 2020, Tamil Nadu is having $2^{\text {nd }}$ largest recovery rate and keeping the fatality rate comparatively less (367 deaths) than many other states and even many other countries. Apart from the control measures, the state has even taken relief measures to the people who are directly or indirectly affected by the pandemic. Monthly financial assistance to about 4 million jobless workers of various sectors, migrant workers and poor is being provided since March. To ensure food safety, the availability of food material supplies at free of cost at state-run "fair price shops" of Tamil Nadu Civil Supplies Corporation and Amma canteens. The relief measures also include the extension of dates for paying various dues. In order to recover the economic losses expert team with former Governor of Reserve Bank of India, Prof. Rangarajan as head has been formed by the state government. On the other side healthcare agencies and research laboratories are working on in developing possible new treatments and vaccines to cure the disease.

Honorable Chief Minister of the state, Dr. K. Palaniswamy penned a letter to the public extending his moral support has stated the stand of the state in various crisis situations like drought, tsunami, various cyclones and floods that hit Tamil Nadu and reminded about how quick the state was back to the normal in all those situations along with the support of the public. 
Impact of COVID-19 and Lockdown: The state is stumbled due to the effects of the COVID-19 pandemic. Although the government at all possible ways is trying at its best in fighting the pandemic, there remains a series of issues making the situation a more complicated one. Most serious issues include people hiding their travel history, escaping of many COVID-19 positive cases from hospitals, and infected persons trying to dodge mandatory home quarantine which causes the indefinite spread of disease mostly in asymptomatic cases ${ }^{[6]}$. The state health minister in a press-meet expressed his frustration about the public not following the precautionary measures such as wearing masks in public places. These delays the state's efforts in controlling the spread of the disease thereby leading to community transmission Although all the control measures are being taken for the purpose of control and prevention of disease, there are various other impacts too. COVID-19 pandemic situation has its impact on different people differently based on their regional, economic, social status, etc. The sudden announcement of the pandemic lockdown has severely affected all the sectors due to an unorganized workforce. The announcement of the lockdown should have been prepared much better. In the urge of addressing the pandemic, we have failed to concentrate on other linked problems. Since many hospitals and healthcare units stopped admitting outpatients with other complaints and decreased the inpatient counts, people have to suffer a lot in meeting their health emergencies other than the pandemic. In addition to that, the lack of transport services and fear of infection has locked the people in their homes. In a state where the birth rate is 15.0 per thousand ${ }^{[9]}$, this situation has affected the pregnant women, postpartum women and neonatal. Since the COVID-19 disease affects the people with underling health conditions, those suffering from chronic diseases, lacking immunizations and whose other medical needs were not addressed may have detrimental health conditions leading them to become an easy host for SARS-CoV-2. Another important issue is the relaxation of the lockdown at the time of increasing cases. However, this can be linked with an increase in the number of tests. Since the numbers are continuing to increase, it is not a good idea to give relaxations in the lockdown protocols. This relaxation can make the condition even worse in the immediate future causing a huge impact.

The measures to reduce the spread of infection has affected economic activities. This has had and having impact on the micro, small and medium enterprises (MSMEs). MSMEs contribute to about one-third of the nation's GDP, with Tamil Nadu being the one among the large contributors which hosts employment of people from all over the nation in various sectors. The closure of production units, firms and various businesses has resulted in the loss of jobs and financial insecurity, in which the most affected are the daily wagers and migrant workers. This has affected a huge number of populations adversely. It is unfortunate that the first death of migrant workers in the country due to the COVID-19 pandemic lockdown happened in the Theni district of Tamil Nadu who struck in the forest fire while walking through a forest. From the Economic Survey 2016-2017 based on Cohort Migration Metric, it is evident that the state has the largest migrant population of about 1 million migrants in 20-29 age during 2001-2011. During 1991-2001 the same was just 26,000 ${ }^{[8]}$. This count shows how much migrant workers would have been affected. Furthermore, it is understood that how much the economy is affected due to the effects of COVID-19 and its control measures. The actual impact on the economy cannot be estimated until the global pandemic comes to an end.

During the pandemic, one of the most affected sectors is the education sector. Most of the educational institutes closed even before the announcement of the lockdown. The closure of schools and higher education institutes with the cancellation of examinations has raised a question of doubt about the capability of the students. Though many of the institutions in the state are making a revolutionarychangeover from face-to-face teaching to providing online teaching to the students, not all the students are able to access this facility. This is due to various reasons, such as the non-availability of electronic devices with everyone, two students from a single home can't share a single computer or gadget, the lack of network, etc. Moreover, this change has caused an increasing burden on the teachers who have to spend extra time in learning about how to use the online teaching portal and is also causing mental distress while handling the students virtually. Not just teachers, students are also facing various difficulties and negative physical and mental effects due to over usage of computers or any other devices. Meanwhile, Violence against women is reported to be increasing during this situation. Shalu Nigam, 2020 has reported various incidents of violence against women in Tamil Nadu ${ }^{[2]}$. Under the Domestic Violence Act 2005, the state has appointed protection officers to move and rescue women who are suffering from domestic violence. 
Future Strategies: As the virus is highly contagious and because of the deficiency of herd immunity, with the current growth rate, various mathematical models have predicted the spread of disease in the state. Dr. G. Srinivas using a mathematical model has predicted that state may witness about 1.3 Lakhs COVID-19 cases with 769 deaths by the end of June. He has also said that about 1.5 lakhs people in the state capital will be infected by mid of July and the infection may reach the peak by the second week of October. Hence there is an urgent need for support from both government and public to reduce the spread and "flatten the curve". Learning from the past and from other countries which are successful in handling the pandemic and prevent the spread, we can consider various possible strategies to help the state recover from this. The authors suggest a concentration on the following strategies to cope up with the situation.

1. Lockdown Extension: Although the extension of lockdown in the past has caused various detrimental effects on daily life, economy, mental and the physical wellbeing of the individuals, it is not the right time to lift the lockdown, especially in the worst affected districts such as Chennai, Chengalpattu, Thiruvallur, Kancheepuram, Thiruvannamalai and Cuddalore. Considering the fact that there is a sharp rise in the number of positive cases, instead of relaxation of the lockdown it is indeed necessary to implement strict lockdown in these districts with additional support from the government to serve the essential needs of the public. Lockdowns implemented so far has effectively supported the transmission of disease. Another strict lockdown will definitely have its impact on limiting the spread and stop the transmission moving to the next level. On implementing strict lockdown in the worst affected regions, sanitized mobile vans to provide daily essentials to the public can be established. This will help in reducing the panic situation among the public, thereby limiting the chances of transmission and administrative officers can have more concentration in eliminating the pandemic. When the decrease in the trend of the cases is witnessed, the lockdown can be relaxed step-by-step.

2. Increased Testing: During the extended strict lockdown, testing for SARS-CoV-2 can be geared up and a large number of populations can be tested, helping in identification, isolation and treatment. Adopting different method for rapid diagnosis of the disease can help in identifying the infected. Many counties affected by COVID-19 pandemic has started conducting large-scale serosurveys to measure the concrete number of COVID-19 cases. Kumar et al. 2020 has suggested a national sero-surveillance protocol to track infection transmission ${ }^{[18]}$. The state can conduct this survey at least in the most affected districts with required modifications. Sapkal et al, 2020 has developed an indigenous IgG ELISA to detect anti-SARS-CoV-2 IgG. This method has been proved to be sensitive as well as specific for the detection ${ }^{[24]}$. This may be helpful in conducting epidemiological surveys. Different strategies for rapid identification such as the use of rapid tests, lateral flow immunoassays and ELISA based tests, drive-through testing, school-based testing are being used in countries like Finland, France, USA, Germany Scotland, etc. $[4,10,11,12,20,21,25,27]$. The neighboring states like Andhra Pradesh, Kerala has largely increased mobile testing centers and walkin mobile kiosks to sample testing. A handful of approaches for surveillance and contact-racing will help the government to choose the most possible between the options.

3. Medical Facilities: The rapid climb in the amount of COVID-19 infections has led to inadequate primary healthcare followed by an undocumented increase of mortalities due to illness other than SARS-CoV-2 infection. The state has to ensure the functioning of hospitals in treating various other health complications such as heart disease, nephrology related problems, diabetes, etc. Since the urban population of the state has access to alternate measures for healthcare needs such telemedicine, tele pharmacy, etc. it is very important to ensure the availability and accessibility of the basic healthcare facilities in the rural regions and the adequacy should be keenly monitored. The immune response of the people with an immune deficiency should be boosted up by available drugs.

4. Travel Monitoring: Usually, all the modes of transports will be overfilled with the crowd. In such a situation, if the public transport is resumed, the situation will get even worse leading to a community spread and failure in controlling the epidemic. It is good to halt public transport until there is a decline in the daily number of cases identified in the state. In order to provide the transport facility, the concept of more number of frequently sanitized vehicles with less number of passengers can be continued. 
5. Business and Economic Revival: In addition to economic grants announced by the Government of India, the state has to announce sector-wise grants which benefit all the affected. The organizations and companies which are paying their employees even during the shutdown should not be neglected. Special grants and aids should be provided to all the business sectors to recover from the loss and economic deficit. In doing so, the state can experience a good comeback from the crisis in the long run.

6. Migrants and Poors: The outflow of the migrants and inflow of people from other districts and states should be monitored. Monitoring the flow will help in keeping the epidemic trend to the lowest possible. In addition to relief funds announced so far, policy decisions can be taken keeping the poor in mind.

7. Education Policies: As the prevalence of pandemic is not definite and complete disease-free situation is not predictable, education of the students should not be affected. Most of the institutions in the state are providing e-learning facility to the students where students are benefitted by the online teaching platforms and resources. However, it is necessary to ensure safe online platforms ensuring the mental well-being of the teachers and students. Guidelines can be formulated in reframing the syllabi to continue delivering quality education during and after the pandemic.

8. Domestic Violence: This pandemic crisis has created a place to renew the thoughts and already existing gender inequalities ideas. The SecretaryGeneral of the United Nations has urged the nations to give priority and support for the arrangement of warning systems for those suffering from family violence ${ }^{[15]}$. In addition to the previous measures taken by the state government in this regard, the government can also start allocating funds to prevent the domestic violence occurring in COVID-19 pandemic situation. And it is essential to take strict actions against the accused to curb the domestic violence.

9. Public Support: In spite of the measures taken by the government in fighting and eliminating COVID-19, this will not be possible without the support from the public. By understanding this crisis situation, it is necessary that people follow all the government advisories, protective measures with patience to control the spread of the disease.
10. Adapt for the Future: It is important to remember the last pandemic, the Spanish flu which horrified the world in 1918 with its effects and aftermath. The Spanish flu lasted for about 2 years. So, this pandemic has had a great impact on the normalcy of the nations, and also more impact is expected in the future. However, with the advancements of the $21^{\text {st }}$ century in various fields of science medical and healthcare facilities, the human race will come out of this tragic situation with more strength and enthusiasm. But it is important to devise a way by which we are going to achieve that. In this crisis situation, people has also understood how much nature and the environment has been exploited and from these lessons we must correct ourselves, with adaptiveness and step forward for a better future.

\section{Conclusion}

The SARS-CoV-2 infection is threatening the world nations with its deadly COVID-19 disease. With no particular treatment method, the healthcare workers are indefinitely working towards the service of the people. Whereas the researchers are tirelessly experimenting on finding a cure or vaccine for the disease. Tamil $\mathrm{Nadu}$ is one of the most affected states in India. Even though the number of positive cases is increasing dayby-day, with the relentless and collective efforts of all the departments of the state, COVID-19 has not yet reached the community spread level. With a population of more than 7 crore people, the state is running very empathically with all its efficiency and past experience in managing the crisis situations. With the experience of the past, and effective numerable control measures along with relief measures, the impact has been decreased and situation is still under control. It is important to continue the efforts to improve the situation and come out of this crisis. The involvement and commitment of the public are very much needed for this cause.

Acknowledgement: Authors acknowledge the tireless efforts of all the healthcare workers, laboratory technicians, researchers and cleanliness workers who have committed themselves in the fight with COVID-19.

Ethical Clearance: Nil

Source of Funding: Meenakshi Academy of Higher Education and Research, Chennai, India

Conflict of Interest: Nil 


\section{References}

1. ICMR COVID Study Group. Laboratory surveillance for SARS-CoV-2 in India: Performance of testing \& descriptive epidemiology of detected COVID-19. Indian J Med Res. 2020;151:424-37.

2. Bai Y, Yao L, Wei T, Tian F, Jin DY, Chen L, Wang M. Presumed asymptomatic carrier transmission of COVID-19. Jama. 2020 Apr 14;323(14):1406-7.

3. Baker MG, Kvalsvig A, Verrall AJ, Telfar-Barnard L, Wilson N. New Zealand's elimination strategy for the COVID-19 pandemic and what is required to make it work. The New Zealand Medical Journal (Online). 2020 Apr 3;133(1512):10-4.

4. Bendavid E, Mulaney B, Sood N, Shah S, Ling E, Bromley-Dulfano R, Lai C, Weissberg Z, Saavedra R, Tedrow J, Tversky D. COVID-19 Antibody Seroprevalence in Santa Clara County, California. MedRxiv. 2020 Jan 1.

5. Carlos WG, Dela Cruz CS, Cao B, Pasnick S, Jamil S. COVID-19 Disease due to SARS-CoV-2 (Novel Coronavirus). American Journal of Respiratory and Critical Care Medicine. 2020 Feb 15;201(4):P7-8.

6. Chetterje P. Gaps in India's preparedness for COVID-19 control. The Lancet Infectious Diseases. 2020 May 1;20(5):544.

7. Covid19India. Coronavirus in India: Latest Map and Case Count. Retrieved June 14, 2020, from http://www.covid19india.org/

8. Department of Economic Affairs. Discussion on Universal Basic Income in the Economic Survey 2016-17: Excerpt. Indian Journal of Human Development. 2017 Aug;11(2):150-9.

9. Department of Economics and Statistics. Statistical Hand Book 2018 (India). Government of Tamil Nadu. Retrieved June 14, 2020, from https://www. tn.gov.in/deptst/stat.htm, 2018.

10. Department of Public Health and Environment. First Set of Results for COVID-19 Blood Test. Retrieved June 14, from https://www.sanmiguelcountyco. gov/CivicAlerts.aspx?AID=492, 2020.

11. Finnish Institute of Health and Welfare. Number of people with coronavirus infections may be dozens of times higher than the number of confirmed cases - Press release - THL. Retrieved June 14, from https://thl.fi/en/web/thlfi-en/-/number-of-peoplewith-coronavirus-infections-may-be-dozens-oftimes-higher-than-the-number-of-confirmed-cases; 2020 .
12. Fontanet A, Tondeur L, Madec $\mathrm{Y}$, Grant $\mathrm{R}$, Besombes C, Jolly N, Pellerin SF, Ungeheuer MN, Cailleau I, Kuhmel L, Temmam S. Cluster of COVID-19 in northern France: A retrospective closed cohort study.

13. Guan WJ, Ni ZY, Hu Y, Liang WH, Ou CQ, He JX, Liu L, Shan H, Lei CL, Hui DS, Du B. Clinical characteristics of coronavirus disease 2019 in China. New England journal of medicine. $2020 \mathrm{Apr}$ 30;382(18):1708-20.

14. Guo YR, Cao QD, Hong ZS, Tan YY, Chen SD, Jin HJ, Tan KS, Wang DY, Yan Y. The origin, transmission and clinical therapies on coronavirus disease 2019 (COVID-19) outbreak-an update on the status. Military Medical Research. 2020 Dec;7(1):1-0.

15. Guterres, A. Make The Prevention And Redress of Violence Against Women A Key Part of National Response Plans For COVID-19 | United Nations. [online] United Nations. Available at: <https:// www.un.org/en/un-coronavirus-communicationsteam/make-prevention-and-redress-violenceagainst-women-key-part> [Accessed 13 June 2020]; 2020.

16. Health and Family Welfare Department. Retrieved June 14, 2020, from https://nhmtn.maps.arcgis. com/apps/opsdashboard/index.html; 2020.

17. Hopkins C, Surda P, Whitehead E, Kumar BN. Early recovery following new onset anosmia during the COVID-19 pandemic-an observational cohort study. Journal of Otolaryngology-Head \& Neck Surgery. 2020 Dec;49:1-6.

18. Kumar D, Malviya R, Sharma PK. Corona virus: a review of COVID-19. Eurasian Journal of Medicine and Oncology. 2020;4:8-25.

19. Kumar MS, Bhatnagar T, Manickam P, Kumar VS, Rade K, Shah N, Kant S, Babu GR, Zodpey S, Kumar CG, Thangaraj JW. National serosurveillance to monitor the trend of SARS-CoV-2 infection transmission in India: Protocol for community-based surveillance. The Indian Journal of Medical Research. 2020 May;151(5):419.

20. LA. County Department of Public Health. (2020, April 20). Preliminary results of USC-LA County COVID-19 study released. Retrieved June 14, 2020, from https://pressroom.usc.edu/preliminaryresults-of-usc-la-county-covid-19-study-released

21. Mallapaty S. Antibody tests suggest that coronavirus 
infections vastly exceed official counts. Nature (Lond.). 2020.

22. Nigam S. COVID-19, Lockdown and Violence against Women in Homes. Lockdown and Violence against Women in Homes (April 28, 2020). 2020 Apr 28.

23. Pulla P. Covid-19: India imposes lockdown for 21 days and cases rise.

24. Sapkal G, Shete-Aich A, Jain R, Yadav PD, Sarkale P, Lakra R, Baradkar S, Deshpande GR, Mali D, Tilekar BN, Majumdar T. Development of indigenous IgG ELISA for the detection of antiSARS-CoV-2 IgG. The Indian journal of medical research. 2020 May;151(5):444.

25. Streeck H, Hartmann G, Exner M, Schmid M. Vorläufiges Ergebnis und Schlussfolgerungen der COVID-19 Case-Cluster-Study (Gemeinde Gangelt). Preprint published online on. 2020 May:04-9.

26. Tang, YW, Schmitz, JE, Persing, DH, Stratton, CW. Laboratory diagnosis of COVID-19: current issues and challenges. Journal of clinical microbiology, 2020; 58(6).

27. Thompson C, Grayson N, Paton R, Lourenço J,
Penman B, Lee LN, Odon V, Mongkolsapaya J, Chinnakannan S, Dejnirattisai W, Edmans $M$. Neutralising antibodies to SARS coronavirus 2 in Scottish blood donors-a pilot study of the value of serology to determine population exposure. medRxiv. 2020 Jan 1.

28. Vellingiri B, Jayaramayya $\mathrm{K}$, Iyer $\mathrm{M}$, Narayanasamy A, Govindasamy V, Giridharan B, Ganesan S, Venugopal A, Venkatesan D, Ganesan H, Rajagopalan K. COVID-19: A promising cure for the global panic. Science of The Total Environment. 2020 Apr 4:138277.

29. Wang W, Tang J, Wei F. Updated understanding of the outbreak of 2019 novel coronavirus (2019$\mathrm{nCoV}$ ) in Wuhan, China. Journal of medical virology. 2020 Apr; 92(4):441-7.

30. World Health Organization. (2020). Infection prevention and control. Retrieved June 14, 2020, from http://www.who.int/emergencies/diseases/ novel-coronavirus-2019/technical-guidance/ infection-prevention-and-control

31. Worldometer. (2020). COVID-19 Coronavirus Pandemic. Retrieved June 14, 2020, from https:// www.worldometers.info/coronavirus/ 